\title{
USING PEER FEEDBACK TO HELP DEVELOP CRITICAL THINKING SKILLS
}

\begin{abstract}
Many first year undergraduate students arrive at university without having been taught how to think critically. This poses a serious problem as without critical thinking skills, students can fall into bad intellectual habits impeding their development. An example of this is the over-reliance on the internet for information. The resulting 'Google-it' mentality can then leave sixth-formers insufficiently prepared for Higher Education; impacting their ability to thrive at university
\end{abstract}

W hy do we care about critical thinking? One of the key graduate attributes is that of being thoughtful and proactive - and at the University of West London, graduates are expected to develop the ability to interpret, analyse and evaluate information. In an environment rife with fake news and 'alternative facts' this is a vital attribute for any student. However, many undergraduates need academic support in the development of such information literacy skills in order to lay the foundations for their studies, future careers and lifelong learning. In order to undertake this effectively, active learning needs to be developed - where students become active participants in the process of information evaluation rather than passive listeners (Bronwell \& Elson, 1991).

Critical thinking has been described as the defining concept of Western Higher Education with Moore (2011) going as far as to say it should be the goal of a Higher Education. Pohl (2011) asserts that one of the primary objectives of education should involve the teaching of tools for lifelong learning. Twenty first century graduates faced with the speed, breadth and depth of the fourth industrial revolution increasingly require creativity, critical thinking and peer collaboration in order to navigate complex, interconnected issues. These graduates are more likely to work across many disciplinary boundaries and thus critical thinking is a valued transferable skill from academia to the workplace. The reality is, however, that while academics assert that graduates possess critical thinking skills, employers disagree (Hart Research Associates, 2013).

\section{Critical thinking in the classroom}

Pohl (2011) describes a classroom thinking culture as a supportive environment where specific factors work together to bring about and reinforce productive thinking in a critical and creative sense. Moreover, Pohl asserts that thinking skills need to be explicitly taught and, while other factors connected to student learning are articulated in guidelines and policies, teaching thinking skills remains a common exception. Pohl, alongside the work of Professor John Hattie (1996) advocated devising a framework to aid teachers in the explicit teaching of thinking skills.

Scaffolding, as a teaching strategy, is known to help promote student learning. A study by van de Pol, Mercer and Volman (2018) on how teachers used scaffolding to support students' learning in small-group work found that scaffolding support in small-group work fostered students' learning; however, crucial to the success of the scaffolding process is the timely fading of this support. Literature discussing the use of scaffolding in Higher Education is rare as the emphasis is on developing the higher order skills of analysis, synthesis and evaluation; concepts that are considered more difficult to scaffold. However, a scaffolding approach was used with computing undergraduate students in Staffordshire University, to introduce a complex, unstructured problem requiring the exploration of a range of different issues. This was linked to assessment to encourage students to engage with the process. The findings revealed that whilst providing good support initially, linking scaffolding to assessments was problematic due to the fading of the support (Stanier, 2015).

As well as scaffolding, peer feedback has been found to assist in the development of critical thinking in students. Wanner and Palmer (2018) found that although formative peer feedback did not lead to improved marks in assignments, students stated that it improved the quality of their work - helping to clarify the strengths and weaknesses in their analysis. Moreover, students with specific learning needs appreciated peer feedback for the added help with editing the work. 

Name:

Introduce your claim

(This is your position on the issue)

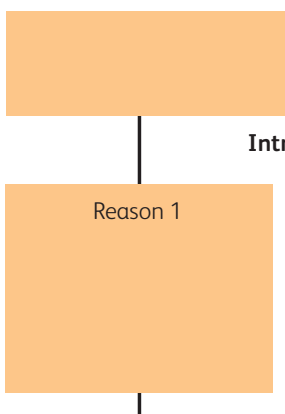

(Provide statistical data facts that can be proved, expert testimony/accounts of personal experience/other evidence)
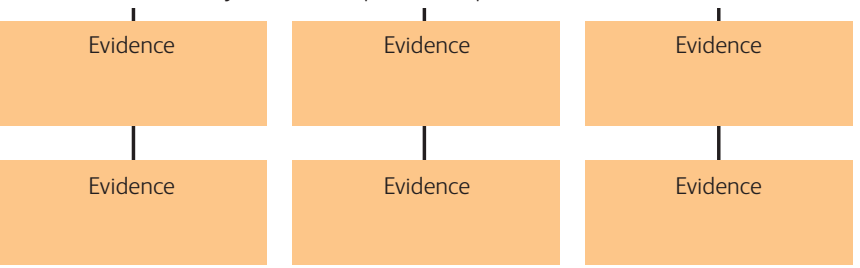

(Share a counterclaim and provide evidence to disprove it)
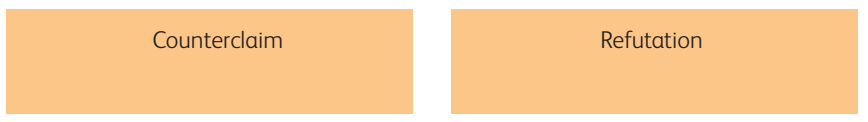

FIGURE 1 Building an argument

\section{Research design}

A classroom intervention activity was designed for first year undergraduate students at the University of West London (UWL) that aimed to encourage critical thinking and test the effectiveness of peer feedback as a tool for developing competence in critical thinking. A scaffolded approach was developed; using two specifically designed handouts. The first helped students critically structure their arguments and the second was used to work in pairs/small groups to evaluate the arguments of peers and provide meaningful feedback.

An active learning approach was used for this project with a group of first year business students who had a summative assessment that took the form of a group discussion (worth 20\% in a core skills-building module). The assessment involved discussion, in small groups, of a highly topical and emotive subject (cyberbullying). Students were required to adopt a position in the discussion and support this with credible academic evidence - while also listening and responding to the opinions of other group members. The assessment was challenging, so, in order to support students, three lessons were planned to introduce students to critical thinking and argument positioning using specifically designed handouts (see Figures $1 \& 2$ ), and utilising peer feedback. The module was delivered by a team of tutors so lesson planning had to be clear in order to be effective in its support of the students. The process is summarised in Figure 3.

Date:

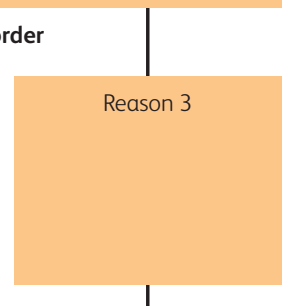




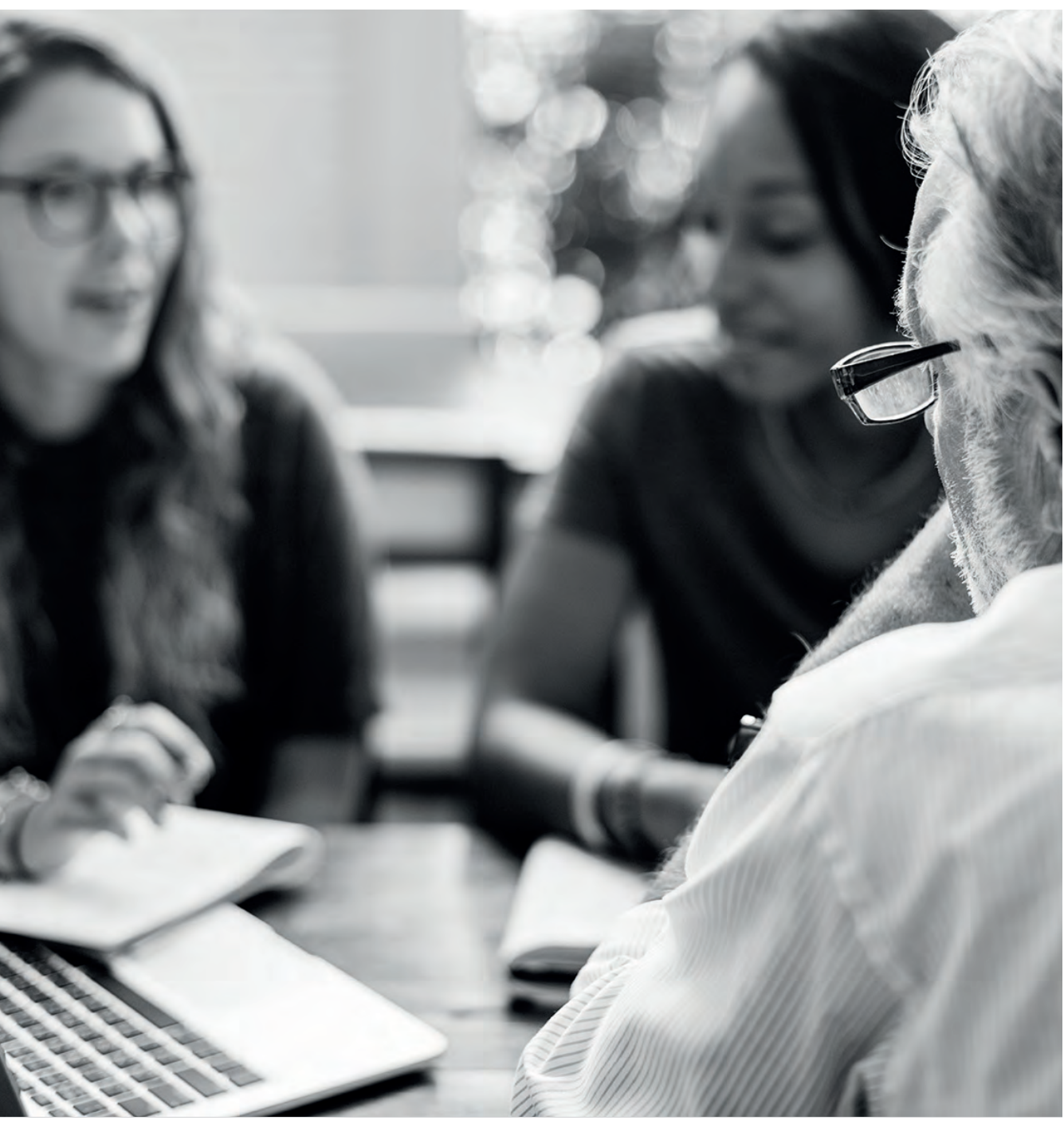

At a meeting to discuss the effectiveness

of the intervention, it became evident

that tutors who had previously felt

hesitant about peer feedback activities

now appreciated the value and were

much more confident about setting

up such activities in their teaching.

Moreover, these tutors also had a clearer

understanding of the importance of

explicitly teaching thinking skills and

facilitating this in a classroom setting

\section{What did the students think?}

Students provided anonymous feedback one week after completion of their assessed group discussion task. This allowed time for them to reflect on the usefulness of the intervention in the development of their critical thinking ability and the extent to which they were able to apply this in their assessment. It was clear from their comments that they had found the structure of both handouts helpful. Ninety-five percent of students commented that the peer feedback process using both handouts increased their competence in critical thinking and all students felt that they better understood the value of peer feedback in skills development. Furthermore, $90 \%$ of students felt that they had performed better in the assessment after the intervention and were anticipating higher marks.

Qualitative data from the student evaluations also showed positive results with comments such as:

"This template helped to structure my points more clearly and come to a more solid point and showed me you can't just say a point without legitimate evidence."

"Helped me structure my argument in a critical way"

"This type of exercise... is actually very handy and helpful for critical thinking"

"It encourages you to use evidence for your argument"

"It helped me organise my thinking and not go off topic which can happen when researching"

These findings are in contrast to Wanner and Palmer's study (2018) where students found peer feedback helpful but that it did not necessarily result in improved marks. The present study also finds itself in contrast with Stainer's research (2015) where linking scaffolding to assessment became problematic; the reason for this difference could be attributed to students having the scaffolding (two handouts) with them and consequently they did not feel abandoned when the tutor's verbal support was gradually faded and replaced with peer feedback.

A further unplanned impact of the intervention was on the confidence of the module team. At a meeting to discuss the effectiveness of the intervention, it became evident that tutors who had previously felt hesitant about peer feedback activities now appreciated the value and were much more confident about setting up such activities in their teaching. Moreover, these tutors also had a clearer understanding of the importance of explicitly teaching thinking skills and facilitating this in a classroom setting. This was a very welcome bonus to the intervention project. 


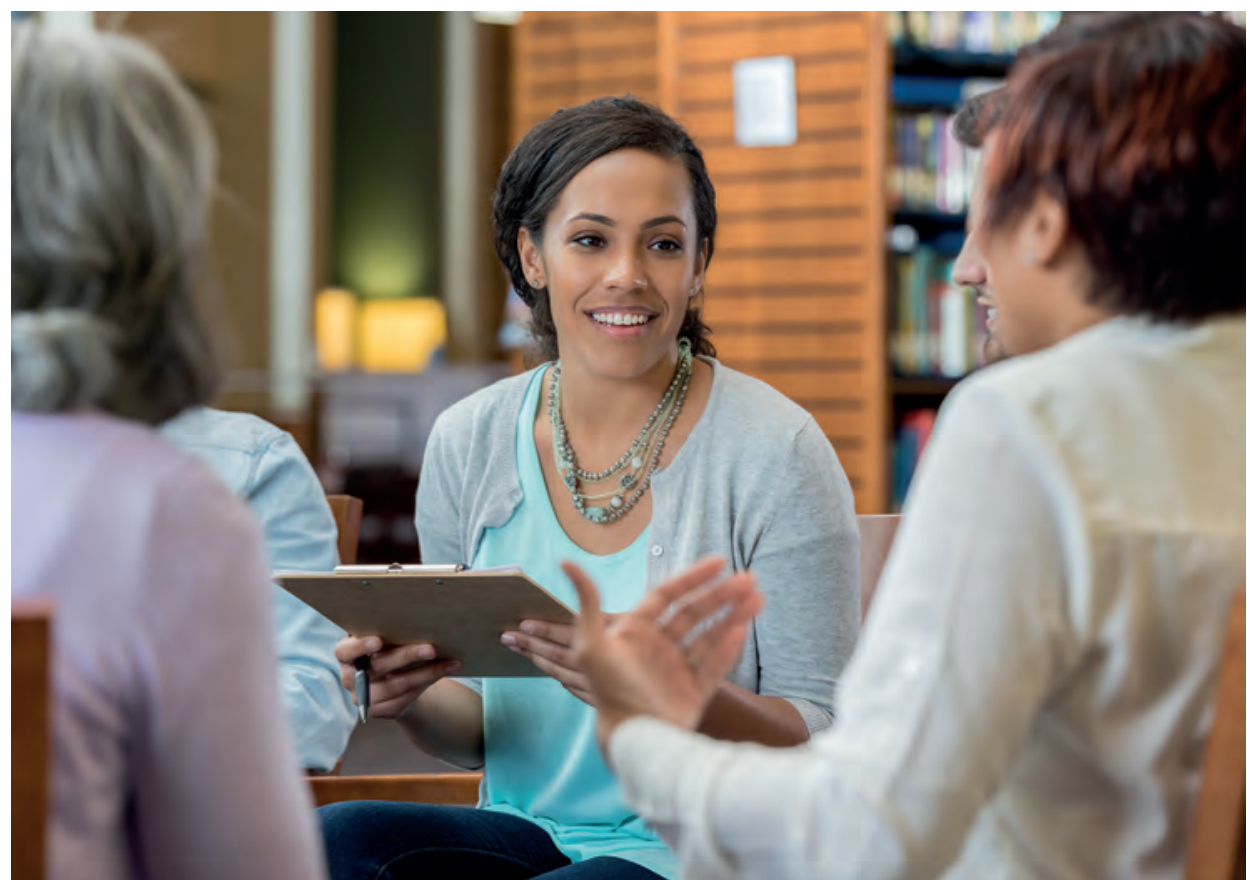

\section{Conclusion}

The most important impact of this project was on the confidence of the students who felt that the intervention placed them in a much better position in terms of their ability to construct and evaluate a critical argument. It helped them realise the value and effectiveness of peer feedback and the explicit support provided by tutors. The overwhelming opinion was that critical thinking is a crucial skill that students value support to develop.

This intervention has the potential to be used as is, or adapted for any discipline taught at first year undergraduate level, to develop students' critical thinking abilities in a supportive environment with peers, where ideas can be tested collaboratively without outside pressures. This research could be further developed with second and final year students in mind, on ways to continue explicitly supporting students in the development of critical thinking.

nv challenge of generic skills and disciplinary discourse.
References

Hattie, J. \& Clarke, S. (2019) Visible learning: Feedback, Routledge: Abingdon, Oxon

Hattie, J., Biggs, J. \& Purdie, N. (1996) Effects of learning skills interventions on student learning: A meta-analysis, Review of Educational Research, 66(2): 99-136

Hart Research Associates, (2013) It takes more than a major: Employer priorities for college learning and student success, Hart Research Associates: Washington DC

Moore, T.J. (2011) Critical thinking and language: The Bloomsbury Academic: London

Stanier, C. (2015) Scaffolding in a Higher Education context. ICERI2015 Proceedings. 8th International Conference of Education, Research and Innovation, 18-20 November 2015, Seville, Spain, 2015. IATED, Seville, Spain, 7781-7790

van de Pol, J., Mercer, N. \& Volman, M. (2018) Scaffolding student understanding in small-group work: Students' uptake of teacher support in subsequent small-group interaction, Journal of the Learning Sciences: 1-34

Wanner, T. \& Palmer, E. (2018) Formative self-and peer assessment for improved student learning: the crucial factors of design, teacher participation and feedback, Assessment \& Evaluation in Higher Education, 43(7): 1032-1047

Pohl, M. (2011) Developing a classroom culture of thinking A whole school approach, TEACH Journal of Christian Education, 5(1): Article 3. Available at: https://research. avondale.edu.au/teach/vol5/iss $1 / 3$

Pohl, M. (2000) Learning to think, thinking to learn. Melbourne, Vic: Hawker Brownlow Education

\section{About the authors}

Yasmin Kulasi, Senior Lecturer in Marketing at University of Westminster

Keywords

Information evaluation, productive thinking, scaffolding

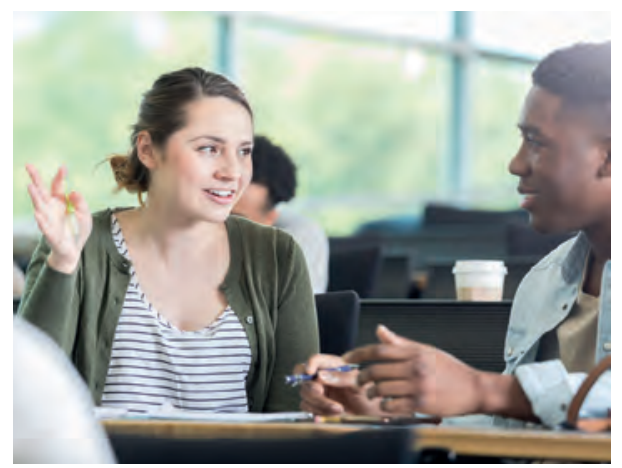

The most important

impact of this project was

on the confidence of the students who felt that the intervention placed them in a much better position in terms of their ability to construct and evaluate a critical argument 